\title{
Translating Evidence in a Priority Setting Partnership: Knowledge Gaps Between Healthcare Providers and Oesophageal Cancer Patients
}

\section{Sarah McDonnell ( $\nabla$ mcdonns3@tcd.ie)}

Trinity College Dublin School of Medicine https://orcid.org/0000-0001-7018-2434

\section{Tara Breslin}

Trinity College Dublin School of Medicine

Mawaheb Elnour

Trinity College Dublin School of Medicine

\section{Bianca Mascan}

Trinity College Dublin School of Medicine

\section{Nur Shuhada Shahruddin}

Trinity College Dublin School of Medicine

\section{Michelle Fanning}

The Trinity St James Cancer Institute

\section{Anthony Galvin}

The Trinity St James Cancer Institute

Jennifer Moore

The Trinity St James Cancer Institute

Narayansamy Ravi

The Trinity St James Cancer Institute John V Reynolds

The Trinity St James Cancer Institute Claire L Donohoe

The Trinity St James Cancer Institute

\section{Research Article}

Keywords: knowledge gaps, cancer, relationships, education, information

Posted Date: February 1st, 2022

DOI: https://doi.org/10.21203/rs.3.rs-1200724/v1 
License: (c) (i) This work is licensed under a Creative Commons Attribution 4.0 International License. Read Full License 


\section{Abstract}

Despite the fact that medical information is now more accessible than ever, knowledge gaps remain between patients and healthcare providers (HCPs). To date, patients' need for information following a diagnosis of oesophageal cancer have not been adequately met.

Purpose: The purpose of this study was to identify why knowledge gaps exist between oesophageal cancer patients and HCPs and how to address them.

Methods: A 7 set question series was developed for use in a patient/HCP focus group in addition to 11 individual phone interviews with survivors of oesophageal cancer. Qualitative semi structured interviews were conducted to explore oesophageal cancer patients' access to information. The data was analysed thematically, which involved coding all patient transcripts before identifying and reviewing key themes.

Results: The three primary themes that emerged were; Opportunity (HCP team factors and relationship development), Ability (Patient factors), and Priority (Pacing of Information Delivery).

Conclusion: Effective communication between patients and HCPs was identified as an integral component to the enhancement of patient knowledge. HCP's should continue to refine and improve methods of information delivery and encourage conversations regarding information preferences. Patients' must be clearly encouraged to ask questions or raise concerns to ensure continuous access to information. A dedicated representative in place to relay these concerns may prove beneficial. Understanding patient values and the external factors that influence how patients understand their health may allow HCP's to make evidence-based recommendations in a way that is individualised to the specific needs of the patient.

\section{Introduction}

Oesophageal cancer is a serious and life altering malignant condition with a 5-year survival rate of less than $20 \%$ [1]. While medical information has never been more accessible than it is today, knowledge gaps remain between patients and healthcare providers (HCPs) within the multidisciplinary team (MDT). Patients diagnosed with oesophageal cancer desire a significant amount of information regarding their illness [2] and healthcare professionals (HCP) tend to underestimate patients' needs for information following a diagnosis of oesophageal cancer [3]. Researchers in our centre have conducted a priority setting partnership for research into oesophageal cancer asking patients, their supporters and healthcare providers to identify key unanswered questions amenable to further research with the aim of generating the top priorities for oesophageal cancer research. Almost half (45\%) of questions submitted by people living with and after oesophageal cancer were already answered by research. The overall purpose of this qualitative study was to explore why, from the patient's perspective, knowledge gaps exist between oesophageal cancer patients and health care professionals (HCP) and how to address them.

\section{Methods}


Patients who participated in the priority setting partnership were asked to provide contact details if they wished to participate in further research studies. Ethical approval was obtained from the hospital research ethics committee. After reviewing the questions submitted by patients that have been already answered by research, three hypotheses were generated by the research group to propose reasons why patient access to medical information and advice regarding these questions may be impaired.

- Resources available but unable to utilise (shock \& fatigue, social/family support, volume of information, geographical location, educational background, patient mindset, timing of information delivery)

- Communication barriers between HCP and patients and among HCPs (i.e. continuity of care, accessibility)

- Efficacy of the patient-HCP relationship (patient willingness to discuss diagnosis/treatment related questions or concerns with HCP, volume of information, continuity of care)

We tested these hypotheses to develop a 7 set question series in a mixed patient/HCP focus group prior to individual patient interviews (supplementary table 1). Three survivors of oesophageal cancer and other allied health professionals (1 surgeon, 1 dietician, 1 liaison, 1 nurse, 1 researcher) participated in a qualitative focus group conducted via Zoom. The focus group followed a semi-structured guide that focused on the participants' experiences throughout their diagnosis, treatment, and survivorship. Patients were asked to reflect on their own experience learning about their condition. Following the focus group, the set of 7 questions was refined to broaden the scope of the interview. Two questions were removed as they achieved the same response, and one new question was created.

Qualitative semi structured interviews were conducted by the research team. Purposive sampling generated participants who were survivors of oesophageal cancer and had previously agreed to be contacted for future research. Participants were selected at random and contacted by email. Following informed consent, 11 phone interviews were conducted by 5 members of the research team, who interviewed 2-3 patients each, using the same set of questions (Table I). Interviews lasted 20-60 minutes. Interviews were audio-recorded using a recording app for Android/iPhone and transcribed using the Trint App transcription feature with the consent of the patient.

An initial "ice breaker" exercise was conducted in which patients were asked to rate their preference for having access to information using 5 health related questions and a modified Information Preference Scale (IPS) [6] (Table 2). The set of 7 questions developed from the hypotheses was utilised to prompt the researcher to discuss key themes. Patients were asked to reflect on their own experience learning about their condition and on how other peoples' experiences might differ from their own (if they didn't personally have difficulty gaining information or if they did have difficulty, why that might have been).

The patient interviews were transcribed and a thematic analysis was conducted using an inductive approach; where the data determined the themes generated. The data was analysed by two different members of the research team, both of whom had not conducted the initial interview. The transcripts 
were first reviewed to establish familiarisation with the data, and then a second time for the application of specific codes to the text. For example, the patient statement "I was very satisfied" received the code patient experience, in order to assign context. Several other codes were generated including overall experience, relationship with the healthcare team, delivery of information, patient attitude, and access to resources. A third review assessing for unlabelled themes was conducted of all transcripts by the senior author (CLD).

Once all transcripts were coded, sub themes were identified. For example, when examining the code of patient experience, it was identified that patients expressed a range of information preferences. This finding was assigned to the sub theme preference for information. Patient statements were taken directly from interview transcripts to support each sub theme. Once all sub themes were identified and patient quotes selected, they were grouped together into larger primary themes based on compatibility (Fig. I ). Three primary themes were developed to represent the secondary sub themes in consolidation with the original research hypotheses (Fig. II). All primary themes, related sub themes, and supporting interview statements were organized into a table (Table III). The three primary themes; Opportunity (HCP team factors and relationship development), Ability (Patient factors), and Priority (Pacing of Information Delivery), were examined to gain an understanding of patients' experiences. Additionally, specific factors reported by patients in helping meet their information requirements were assessed. A table was generated to demonstrate instances of good practice within each identified theme (Table IV).

\section{Results}

Of the 11 patients who participated in this study (mean age $=65 \mathrm{yrs}$ old, $\mathrm{M}=81.1 \%$ and $\mathrm{F}=18.9 \%$ ), 5 resided in an urban location, 4 rural, 1 semi-rural, and 1 sub-urban. Over half of the participants (54.5\%) completed their secondary education, while $45.5 \%$ obtained higher education.

The IPS measure for information preference (Table II) concluded that the majority of the patients interviewed would "definitely want to know" information if it was made accessible to them. $54.5 \%$ of the patients answered "definitely want to know" when asked if they would want to know how long they were expected to live. Information preferences according to the type of information were generally consistent for each participant (i.e. health related preferences were the same as general information preferences) (Table II).

The hypotheses proposed by the research team were used to refine three primary themes developed from the thematic analysis. None of the original hypotheses demonstrated a direct association with any of the primary themes, however, there was overlap between the initial research hypotheses and primary themes/ secondary sub themes identified (Fig. II). Patient and HCP team related factors (i.e. Patient mindset, trust in the HCP team) were hypothesized to contribute to patients' information needs. This link was confirmed by thematic analysis. Pacing of information delivery emerged as a new theme, however, some of the associated sub themes were also originally proposed as contributing factors by the research team (i.e. continuity of care). 
The data identified that most patients felt they received adequate information regarding their condition and that there were no barriers to accessing information. Patients demonstrated a spectrum of information preferences. One patient described not wanting to know any information about the procedure: "I never, ever wanted to know one thing about the operation. I just did not want to know the gory details. I didn't look it up on Google and I didn't want to talk about it." (Patient 2) In contrast, another patient chose to conduct independent research: "I am a person who always wants to know all the information." (Patient 4) The results from the IPS corresponded with these findings.

Patients' educational background and previous experience within the healthcare system may impact their ability to understand and interpret the information communicated to them. One of the patients stated that they believed that their history of health issues better prepared them for the delivery of information: "I would say the fact that I'd been through major health issues before maybe geared me better to managing the flow of information to and from the various doctors and specialists I was dealing with."(Patient 10) Other patients also highlighted that their geographical location and proximity to services like support groups impacted access to information: "I didn't know any of that existed especially for people in rural parts like myself." (patient 9)

Family and external support was discussed by multiple patients: " $X$ " was there, and she wrote down all the information" (patient 6) and "my partner is a retired allied health practitioner and to me that was the key because I didn't understand the medical terms...I'd never been sick..." (patient 8 ) There was also a range of patient attitudes demonstrated between interviews. Patients who reported no unanswered questions also demonstrated traits of resilience and positive mindset. One patient stated that "positivity will get you through a lot of it..." with reference to his cancer journey. (patient 8) The patients who reported greater trust in their HCP and MDT also reported that most of their questions were answered. Similarly, those that described a trusting relationship with their HCP believed that they had access to all the information they needed. A patient remarked on his satisfaction: "the oncologist or surgeon told me what was happening and basically told me this is what's wrong and this is what needs to be done." (patient 8)

Patient willingness to seek clarification was identified as a determinant to information access. A patient who did not seek clarification stated he was unaware that he could ask questions. "It wasn't properly made clear that if you didn't understand it, maybe ask your doctor." (patient 1) Another patient acknowledged how individual differences could also account for this hesitation. "I know that people might not be as vocal and might not get as much from it, and it's a difficult experience for them." (patient 8)

\section{OPPORTUNITY $\rightarrow$ HCP Team Related Factors and Relationship Development}

Patients reported fewer unanswered questions when there was continuity of care, personalised care, and when an HCP was accessible (i.e. phone, text, e-mail, etc.). One patient reported that continuity of care 
post-treatment was critical to their recovery and access to information. "The follow-up visits with the team were essential for both my mental and physical health." (patient 6)

Most of the patients reported sufficient continuity of care. One patient described: "anytime I went to $Y$ hospital they sent information over to my other oncologist. I think the $\mathrm{X}$ private hospital has the file on computers now anyway, it's an easier method to make sure that your information goes forward and back easily." In contrast, failed continuity of care caused another patient to feel unsure of next steps. "The physios were in the hospital and they were around to walk me around the wards, but they never actually told me what I was supposed to do or continue to do. I didn't get any sort of information." (patient 9) In some cases, offering personalised care led to fewer unanswered questions and a more positive experience overall. In one interview, the patient reported that the doctor was accommodating to the patient's personal goal to return to work: "he came back to me the next day and he said, so you want to go back to work...we better start working on that and they gave me all the advice." (patient 7)

\section{PRIORITY $\rightarrow$ Pacing of Information Delivery}

There were fewer unanswered questions when the information provided to the patient was in terms that the patient could understand. Patients reported a greater sense of understanding when the information was tailored to individual preferences and properly paced with changing information requirements over time.. The volume of information and timing of delivery played a role in whether or not patients were able to adequately interpret the information. "Information overload" impeded some patients from getting answers to their questions.

When discussing barriers to accessing available resources, one patient stated that "if there was one barrier (to accessing available resources) it was my ability to interpret all the information...my ability to interpret and absorb everything." (patient 1) It was mentioned by another patient that understanding the information that they were provided ensured their compliance with treatment. "I think knowing the information really helps. You're more likely to adhere to the regimen because you understand how important it is." (patient 4)

Patients were more satisfied when the HCP team ensured that the delivery of information was appropriate in volume and timing. One patient described their HCP approach as "very good, it was clear, it was concise, and the information he gave us was timely. He didn't give us all the bad news at the start." This patient also reflected positively on his experience stating that the HCP team provided " just enough (information) to keep me sorted." (patient 10). In contrast, another patient described: "I felt it was a huge dump of information, I was trying to process it all, you know, and on top of that, trying to deal with the situation emotionally, the fact that you have cancer... you're trying to process it all at the same time." (patient 1)

Multiple patients reported that face-to-face communication was the most effective method of information delivery. Supplementation of verbal communication with visual and written resources (ie. videos, pamphlets) enhanced patient access to information and bridged gaps in understanding. Social 
support groups and awareness of these additional resources improved access to information by facilitating the sharing of experiences and information between patients.

Several patients reported that HCPs went above and beyond to ensure that they had access to any information/resources that they needed. Communication among HCPs provided smooth transitions of care and minimized the number of unanswered patient questions. HCP accessibility, specifically a dedicated team member available to patients, provided a constant source of information and open line of communication between patients and their HCP.

Fewer questions were left unanswered when the volume of information and pacing of delivery was timed to suit the individual patient's needs. HCP consideration for patient information preferences strengthened trust and improved personalization of care.

\section{Discussion}

The majority of patients who participated in this study reported that they received adequate information regarding their condition and experienced no limitations to accessing information. Patients were most satisfied when the information that they received was delivered by a trusted HCP and tailored to their individual needs.

Due to personal preferences for information, some patients elected to receive only a select volume of information while others sought out as much information as possible. Careful consideration of patient information preferences may prove beneficial.

The majority of patients interviewed reported that a face-to-face approach when delivering information is most effective. This has not been proven in the literature to date. It has however been proven that enhanced communication and relationships between patients and HCPs leads to greater compliance and clinical outcomes $[16,17,18,19]$. Furthermore, due to the global COVID-19 Pandemic, face-to-face consultations have been minimized and the implications of this on patients' understanding are yet to be investigated. Several patients also reported that supplementation with visual modes such as diagrams and videos were informative and effective interactive strategies. This corroborates findings that visual cues enhance satisfaction with the processing of information [17]. Geographical location and proximity services such as support groups directly impacted patient access to information; a finding supported by the literature $[8,9]$.

Patients who reported that they had no unanswered questions demonstrated traits of resilience and positive mindset. This is a novel finding. A larger sample size with a more diverse range of responses from multiple hospitals may prove useful. This finding does however corroborate a study by Farber et al. which demonstrated that resilience is associated with "lower psychological distress," "more positive personal beliefs" and "and lowered belief in controllability of life events." [10] 
Patients reported having greater sense of support and continuity of care when a HCP or associated team member was available and easily accessible (i.e. by text/ voicemail/ phone call). Most patients described the relationship with their HCP team as positive. Some patients also highlighted the relationship with the liaison nurse specifically, who was not only instrumental in ensuring that patients felt heard by addressing questions/concerns promptly, but also communicated effectively within the HCP team. Continuity of care, access to resources and patient experience was improved with efficient communication among HCPs both in the hospital and at the community level.

It remains unclear whether it is beneficial to encourage independent patient research. At present, many HCPs raise concern regarding the use of Google as a method of independent research due to the inaccuracy of sources [14]. Patient-HCP discussions regarding reliable search engines or signposting of appropriate sources of information could prove beneficial. Information therapy [7] or another method of guiding patients toward reliable resources could prove beneficial in bridging knowledge gaps if patients express interest in independent research.

Open communication between the HCP and the patient is vital to ensure that they receive all of the information that they need. Enhanced patient advocacy and facilitation of patient-directed care may reduce gaps in knowledge. The delivery of information should also be timed appropriately and be manageable in volume. Attempts at ameliorating a knowledge gap might be unintentionally exacerbated by providing too much information at one time. The HCP must carefully consider this so as not to overwhelm the patient. D' haese et al. found that a step-wise delivery format reduces patient anxiety. [12]

There are several limitations and sources of bias to the study. Patients self-selected to participate in further research and all were satisfied with the care they received. All the participants felt that they received sufficient information based on their personal preferences, and as such, this study does not address the experiences of patients who don't meet these criteria. There may also be cultural issues associated with how Irish people view healthcare professionals, as there is a strong theme of trusting the doctor or team, and by extension, there may be a hesitancy to challenge or ask questions. Interviews were conducted by medical students and as a result, patients may have felt it important to speak positively about their care to those in training. This study was also conducted during the early phases of the COVID19 pandemic when public responses to healthcare professionals may have been more positive than usual. [20]

\section{Conclusion}

Medical information is now more accessible than ever, however, knowledge gaps remain between patients and healthcare providers (HCPs). The findings of this study confirm that patients demonstrate a spectrum of preferences in terms of disclosure of information.. Health literacy and previous experiences may impact patients' ability to understand and interpret information. Family and social support was beneficial in relaying information to the patient, prompting additional research, and sourcing questions. Patient resilience can either positively or negatively affect the ability to absorb and interpret information, 
as patients reporting no unanswered questions demonstrated traits of resilience and positive mindset. The importance of tailoring information provided to individual patient preferences and proper selection by HCP of when to deliver information also proved beneficial, as this led to fewer unanswered questions.

\section{Practical Value}

The findings of this study have several implications. Despite individual differences, most oesophageal cancer patients emphasised that face to face interaction was paramount to a strong relationship with their HCP and improved access to information. The HCP must come to understand individual patient needs and encourage dialogue regarding information preferences. Understanding the individual goals and values of patients, as well as the external factors that influence how patients understand their health may allow HCPs to make evidence-based recommendations individualised to the specific needs of a patient. Enhanced patient-HCP discussion regarding how to identify credible health resources online and in the community may prove beneficial for both the patient and provider.

Future research should focus on understanding the experiences of patients who report their information requirements are not met.

\section{Declarations}

\section{Funding}

The authors declare that no funds, grants, or other support were received during the preparation of this manuscript.

\section{Competing Interests}

The authors have no relevant financial or non-financial interests to disclose.

\section{Availability of Data and Material}

The authors confirm that the data supporting the findings of this study are available within the article and its supplementary materials.

\section{Code Availability}

Not Applicable.

\section{Author Contributions}

All authors contributed to the study conception and design. Material preparation, data collection and analysis were performed by Tara Breslin, Mawaheb Elnour, Bianca Mascan, Sarah McDonnell, and Nur Shuhada Shahruddin. The first draft of the manuscript was written by Sarah McDonnell and all authors commented on previous versions of the manuscript. All authors read and approved the final manuscript. 


\section{Ethics Approval}

Approval was obtained from the ethics committee of Trinity College Dublin and St James Cancer Institute. The procedures used in this study adhere to the tenets of the Declaration of Helsinki.

\section{Consent to Participate}

Informed consent was obtained from all individual participants included in the study.

\section{Consent to Publish}

The authors affirm that human research participants provided informed consent for publication of the identifying information and statements in Table I-IV.

\section{References}

1. National Cancer Registry Ireland (2019) Cancer in Ireland 1994-2017 with estimates for 2017-2019: Annual report of the National Cancer Registry. NCRI, Cork, Ireland.

2. Wittmann E, Beaton C, Lewis WG, Hopper AN, Zamawi F, Jackson C, Dave B, Bowen R, Willicombe A, Blackshaw G, Crosby TD. Comparison of patients' needs and doctors' perceptions of information requirements related to a diagnosis of oesophageal or gastric cancer. Eur J Cancer Care (Engl). 2011 Mar;20(2):187-95. doi: 10.1111/j.1365-2354.2009.01169.x. PMID: 20345454.

3. Andreassen S, Randers I, Näslund E, Stockeld D, Mattiasson AC. Information needs following a diagnosis of oesophageal cancer; self-perceived information needs of patients and family members compared with the perceptions of healthcare professionals: a pilot study. Eur J Cancer Care (Engl). 2007 May;16(3):277-85. doi: 10.1111/j.1365-2354.2006.00742.x. PMID: 17508949.

4. O’Donohoe C. Oesophageal cancer priority setting partnership. In press 2021.

5. Hunter NL, O'Callaghan KM, Califf RM. Engaging Patients Across the Spectrum of Medical Product Development: View From the US Food and Drug Administration. JAMA. 2015;314(23):2499-2500. doi:10.1001/jama.2015.15818

6. Ho EH, Hagmann D, Loewenstein G. Measuring information preferences. Management Science. 2021 Jan;67(1):126-45.

7. Sonika R, Sharma VL, Singh A. Information Therapy: Bridging the information gap between doctors and patients. South East Asia Journal of Public Health. 2014;4(2):47-50.

8. Cavalieri M. Geographical variation of unmet medical needs in Italy: a multivariate logistic regression analysis. International journal of health geographics. 2013 Dec;12(1):1-1.

9. Santana P. Ageing in Portugal: regional iniquities in health and health care. Social Science \& Medicine. 2000 Apr 1;50(7-8):1025-36.

10. Farber EW, Schwartz JA, Schaper PE, Moonen DJ, McDaniel JS. Resilience factors associated with adaptation to HIV disease. Psychosomatics. 2000 Mar 1;41(2):140-6. 
11. Wartman SA, Morlock LL, Malitz FE, Palm EA. Patient understanding and satisfaction as predictors of compliance. Medical care. 1983 Sep 1:886-91.

12. D' haese S, Vinh-Hung V, Bijdekerke P, Spinnoy M, De Beukeleer M, Lochie N, De Roover P, Storme G. The effect of timing of the provision of information on anxiety and satisfaction of cancer patients receiving radiotherapy. J Cancer Educ. 2000 Winter;15(4):223-7. doi: 10.1080/08858190009528702. PMID: 11199240.

13. Silver MP. Patient perspectives on online health information and communication with doctors: a qualitative study of patients 50 years old and over. Journal of medical Internet research. 2015; 17(1):e19.

14. Murray E, Lo B, Pollack L, Donelan K, Catania J, Lee K, Zapert K, Turner R. The impact of health information on the Internet on health care and the physician-patient relationship: national US survey among 1.050 US physicians. Journal of medical internet research. 2003;5(3):e17.

15. Ong LM, De Haes JC, Hoos AM, Lammes FB. Doctor-patient communication: a review of the literature. Social science \& medicine. 1995 Apr 1;40(7):903-18.

16. Van Weert JC, van Noort G, Bol N, van Dijk L, Tates K, Jansen J. Tailored information for cancer patients on the Internet: effects of visual cues and language complexity on information recall and satisfaction. Patient Education and Counseling. 2011 Sep 1;84(3):368-78.

17. Liu X, Sawada Y, Takizawa T, Sato H, Sato M, Sakamoto H, Utsugi T, Sato K, Sumino H, Okamura S, Sakamaki T. Doctor-Patient communication: a comparison between Telemedicine consultation and face-to-face consultation. Internal Medicine. 2007;46(5):227-32.

18. Onyechi N, Babalola Y. Doctor-Patient Communication: Percep-tion of Doctors' Communication Skills among Patients in Selected Hospitals in Ibadan Nigeria. Journal of Management and Social Sciences. 2020 Dec 11;9(2).

19. Ha J.F., Longnecker N. Doctor-patient communication: a review. Ochsner Journal. 2010 Mar 20;10(1):38-43.

20. Hillard, M., Falvey, D., O'Halloran, M. “COVID-19: Ireland stops to give road of applause for front line workers” The Irish Times. 2020 Mar 26; www.irishtimes.com/people/

\section{Tables}

Table I. Patient Demographics 


\begin{tabular}{|llllll|}
\hline $\begin{array}{l}\text { Patient } \\
\text { number }\end{array}$ & Age & Gender & $\begin{array}{l}\text { Location } \\
\text { (urban/rural) }\end{array}$ & $\begin{array}{l}\text { Highest level of } \\
\text { education }\end{array}$ & $\begin{array}{l}\text { Year of cancer } \\
\text { diagnosis }\end{array}$ \\
\hline 1 & 68 & male & Semi-rural & Higher & 2018 \\
\hline 2 & 72 & male & rural & Secondary & 2017 \\
\hline 3 & 70 & female & urban & Secondary & 2009 \\
\hline 4 & 70 & female & rural & Higher & 2017 \\
\hline 5 & 44 & male & rural & Higher & 2016 \\
\hline 6 & 62 & male & rural & Secondary & 2011 \\
\hline 7 & 85 & male & urban & Higher & 2015 \\
\hline 8 & 49 & male & urban & Secondary & 2018 \\
\hline 9 & 67 & male & urban & Secondary & 2010 \\
\hline 10 & 65 & male & sub-urban & Higher & 2016 \\
\hline 11 & 65 & male & urban & Secondary & 2016 \\
\hline
\end{tabular}

Table II. Modified IPS Measure for Information Preference

I will ask you 5 questions and if possible, please respond with "Definitely Don't Want to Know (DD), Probably Don't Want to Know (PD), Definitely Want to know (DW), or Probably Want to Know (PW)." 


\begin{tabular}{|llllll|}
\hline Patient & Question 1 & Question 2 & Question 3 & Question 4 & Question 5 \\
\hline 1 & PW & PW & PW & PW & PW \\
\hline 2 & PD & PD & PD & PD & PD \\
\hline 3 & DW & DW & DW & DW & DW \\
\hline 4 & DW & DW & DW & DW & DW \\
\hline 5 & DW & DW & DW & DW & DW \\
\hline 6 & DD & PD & PD & PD & PD \\
\hline 7 & DW & DW & DW & DW & PW \\
\hline 8 & PD & DW & DW & PW & DW \\
\hline 9 & DD & DD & PW & DW & DW \\
\hline 10 & DW & DW & DW & DW & DW \\
\hline 11 & DW & DW & DW & DW & DW \\
\hline
\end{tabular}

Table III: Primary Themes and Associated Patient Statements 


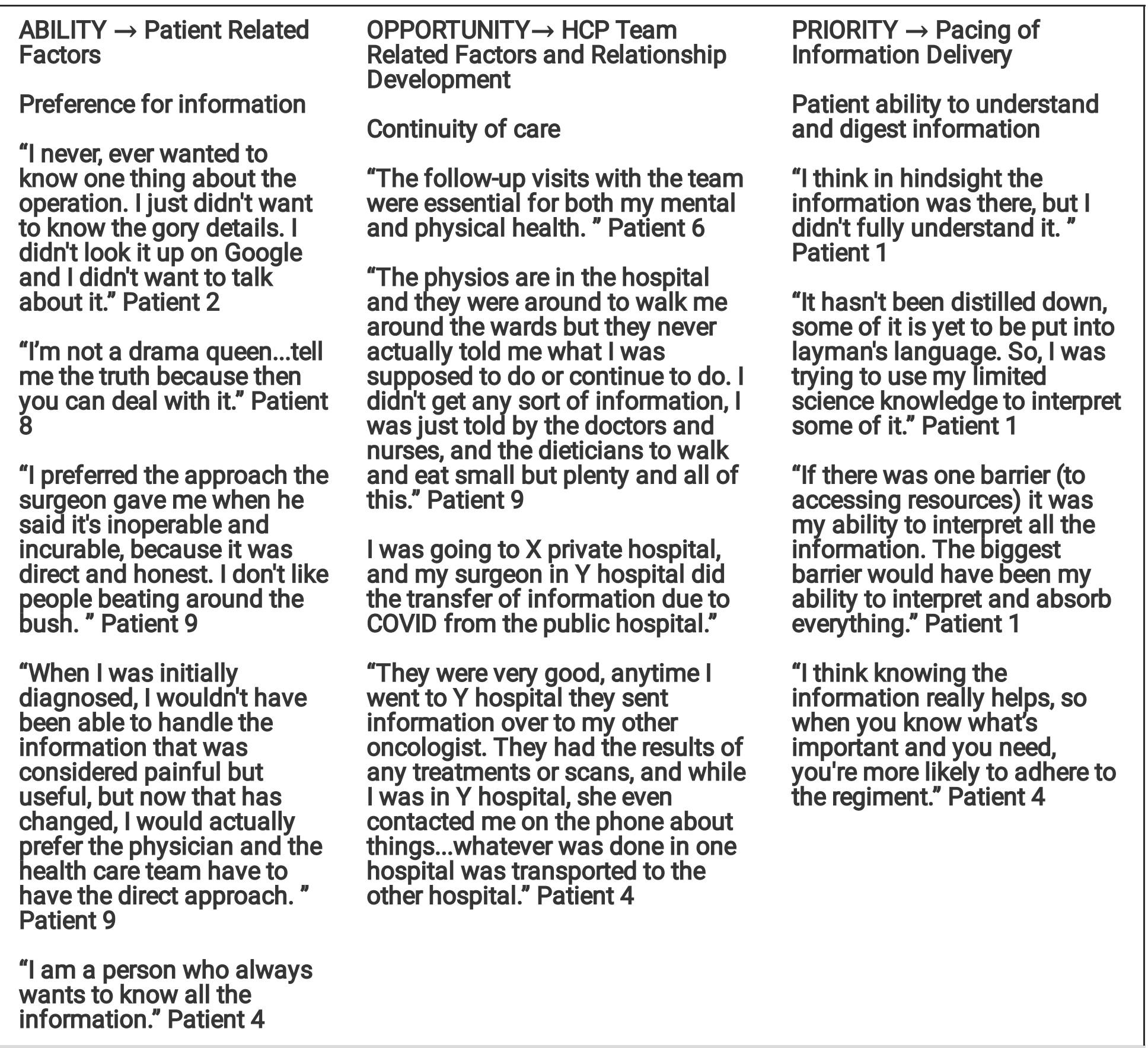


Education background \& experience

"As an allied healthcare professional, I have quite a bit of information. I suppose the fact that I knew a bit, what I was taking the day before I went along because I understood what they were telling me."

"I would probably have asked fewer questions if I worked in a different field." Patient 4

"I would say the fact that I'd been through major health issues before may have geared me better to managing the flow of information to and from the various doctors and specialists I was dealing with." Patient 10

\section{Psychological state}

"But the initial diagnosis, it was a bombshell, I was walking around beside myself." Patient 9

“Everybody's different and everybody suffers in different ways and is mentally affected in different ways." Patient 8
Accessibility

"Anything that I ever had to talk to her about, she was there. If she didn't answer, the phone would ring later. She'd always get back, you know, which was very reassuring." Patient 2

"I can talk to my liaison (by text), she does a fine job on her busy day texting me back quickly....and that's all I want....I could approach any of them no problem at all." Patient 8

"She (liaison nurse) made everything more bearable, enabled me to feel at ease."

“I couldn't praise her (liaison nurse) enough." Patient 3
Volume of information

"I felt it was such a huge dump of information, I was trying to process it all, you know, and on top of that, just trying to deal with the situation that you're emotionally trying to deal with, the fact that you have cancer...But, you're trying to process all at the same time." Patient 1

“He didn't give me a huge amount of information. Just enough, enough to keep me sorted, you know." Patient 10
Timing of information delivery "His approach was very good, was clear, it was concise, and the information he gave us was timely. He didn't give us all the bad news at the start." Patient 10 
Geographical location (rural vs urban and proximity to home)

"I didn't go down the road of support groups but that was my own personal choice. I mean I don't drive. That was kind of a factor (but I didn't feel I was losing out because of that.) It was just my own personal choice."

Patient 3

"I only found out about the services and accommodation around 18 months after my surgery, I had none of that for the duration of my treatment."

"I didn't know any of that existed especially for people in rural parts like myself. Patient 9

Social/Family support

" $\mathrm{X}$ was there, and she wrote down all the information." Patient 6

"My partner is a retired allied healthcare professional and to me that was the key because I didn't understand the medical terms...I'd never been sick..."

"My wife does more of the reading for me and then explains it to me." Patient 8

"I thought I was going to have a nervous breakdown; my wife was the person I turned to."

"I turned to my friends and wife." Patient 9
Personalized care

Doctor " $X$ " was accommodating of patient's own goals- "he come back into me the next day and he said, so you want to go back to work...we better start working on that and they gave me all the advice"
Independent patient research

"A lot of people use Doctor Google and now they're beginning to see that it has benefits... you know if it's used in the right way." Patient 1

"The doctor said, you need to be careful with this kind of stuff because you might be getting stuff that isn't really medically sound."

Patient 10 
Patient attitude and mindset

"I had no problem taking any advice that I got there....and I kind of had to reinvent myself in a way in the eating habits and whatever...it was very tough in the beginning" Patient 7

"For me the big thing is you've got to be disciplined with yourself..." Patient 7

"Positivity will get you through a lot of it too..." Patient 8

"Some people are the kind of people that would find faults even if things were perfect..." Patient 3

Trust in HCP

"You're only as good as what the medics tell you, if you listen to them. " Patient 7

"I'm happy when I have the oncologist or surgeon tells me what's happening and basically told me this is what's wrong and this is what needs to be done."

Patient 8 
Willingness to seek

clarification on unanswered

questions or concerns

"It wasn't properly made clear that if you didn't

understand it, maybe ask

your doctor."

"I think in hindsight the information was in there, but I didn't fully understand

it." Patient 1

"Nobody told me to come down off them (morphine patch) gradually. I suddenly felt really depressed and I was crying...I just didn't know. It was just ignorance on my part." Patient 3

"I know that people might not be as vocal and might not get as much from it, and it's a more difficult experience for them."

Patient 8

Table IV: Examples of Good Practice Within Each Identified Theme 


\section{ABILITY $\rightarrow$ Patient Factors}

Verbal information delivered by trusted member of HCP best source of information

Supplementation of verbal and written resources with visual videos were effective and informative interactive strategies

Benefit of shared patient experience to information access modes such as diagrams and

"He (professor) kindly went over the diagnosis with me again, you know, very caring and effective." Patient 1

"For me, it was mainly verbal information." Patient 2

"They had a CD; I actually have it here. The patient is shown it, and it's the oesophageal cancer treatment. I found that very good." Patient 9

"I particularly found the video really good because it gave me a visual image." Patient 10

"It (support group) was very good to go there to see other people and see how they responded to different things." Patient 2

"Information sessions sharing talks on the latest state of knowledge on oesophageal cancer, what the treatments are, what the possibilities are. People who are at different stages of the illness are getting together for coffee mornings and just sharing their experiences." Patient 10

The impact of positive attitude/mindset on patient experience
"I went within minutes of having a poor, desperate diagnosis to say look, I'm positive. What can I do to make sure that my journey is going to be the best possible one going forward?" Patient 1

"Positivity will get you through a lot of it too I have to say. I believe anyway." Patient 8

\section{OPPORTUNITY $\rightarrow$ HCP team factors and relationship development}

Continuity of Care provided by MDT post-treatment
"It's been continuous, l've had regular scans, and contact and when I had the re-occurrence, I had to go to surgery the second time round and I found the multidisciplinary team very helpful. The whole team was brilliant." Patient 4

"The follow-up visits with the team were essential for me, for both my mental and physical health." Patient 6

"If you had anything to worry about, you dropped a phone call." Patient 1

"I had a phone number available 24 hours. The professor and his secretary were great. Very, very helpful." Patient 2

"If she didn't answer, the phone would ring later. She'd always get back, you know, which was very reassuring." Patient 2 


\begin{tabular}{|c|c|}
\hline ABILITY $\rightarrow$ Patient Factors & \\
\hline $\begin{array}{l}\text { Patient self-reflection on the } \\
\text { relationship shared with the MDT }\end{array}$ & $\begin{array}{l}\text { "I couldn't say one bad word about them. I'm talking from the } \\
\text { head man down to the person making the beds. I couldn't ask for } \\
\text { better." Patient } 2\end{array}$ \\
\hline & $\begin{array}{l}\text { "Everybody was just second to none, really. I couldn't say no } \\
\text { fault whatsoever." Patient } 3\end{array}$ \\
\hline & $\begin{array}{l}\text { "I can't say enough. I could be here telling you all day how } \\
\text { wonderful you all are. And that is just a fact." Patient } 7\end{array}$ \\
\hline & “There was no stone unturned." Patient 2 \\
\hline $\begin{array}{l}\text { PRIORITY } \rightarrow \text { Pacing of } \\
\text { information Delivery }\end{array}$ & \\
\hline $\begin{array}{l}\text { HCP delivery of information } \\
\text { tailored to individual patient } \\
\text { needs }\end{array}$ & $\begin{array}{l}\text { "The timing of the information was apt because l'm not so sure } \\
\text { we'd have been able to handle that information just after the } \\
\text { surgery." Patient } 10\end{array}$ \\
\hline & “He broke it up into bite sized milestones." Patient 10 \\
\hline $\begin{array}{l}\text { Quality and Quantity of the } \\
\text { information accessible to } \\
\text { patients }\end{array}$ & $\begin{array}{l}\text { "The resources that were made available by the team were } \\
\text { massive. And you kind of felt that. Nothing was left off the table } \\
\text { in terms of your treatment, you know." Patient } 10\end{array}$ \\
\hline & $\begin{array}{l}\text { "I had a recent scare and he would call me or email me on a } \\
\text { Sunday, on his day off, just to make sure that I was okay." } \\
\text { Patient } 5\end{array}$ \\
\hline $\begin{array}{l}\text { Personalization of care by the } \\
\text { MDT to suit patient needs }\end{array}$ & $\begin{array}{l}\text { "He (professor) came back in to see me the next day and he said," } \\
\text { so you want to go back to work... we better start working on that." } \\
\text { Patient } 7\end{array}$ \\
\hline
\end{tabular}

\section{Figures}




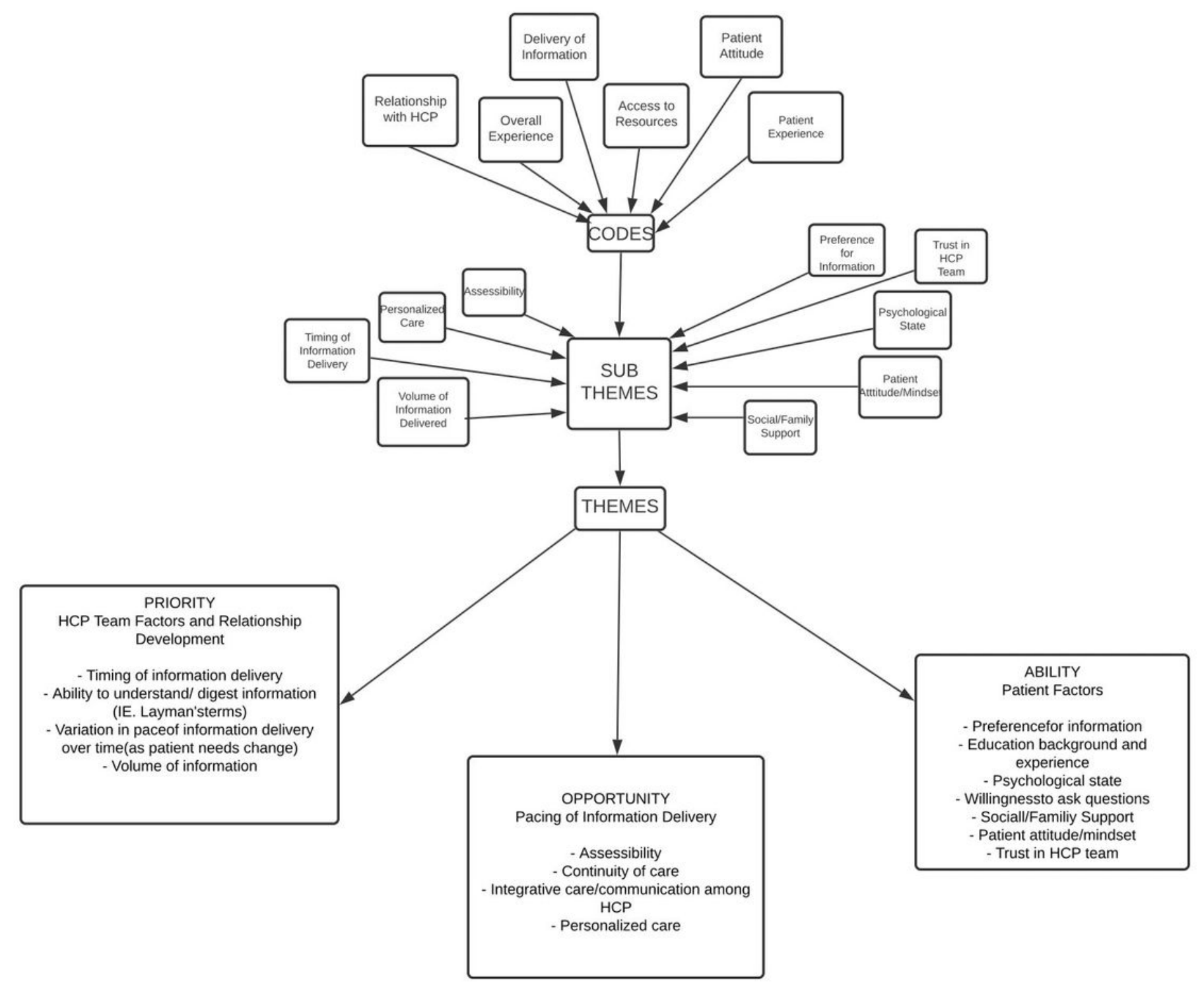

Figure 1

Development of Primary Themes from Secondary Sub Themes and Codes 


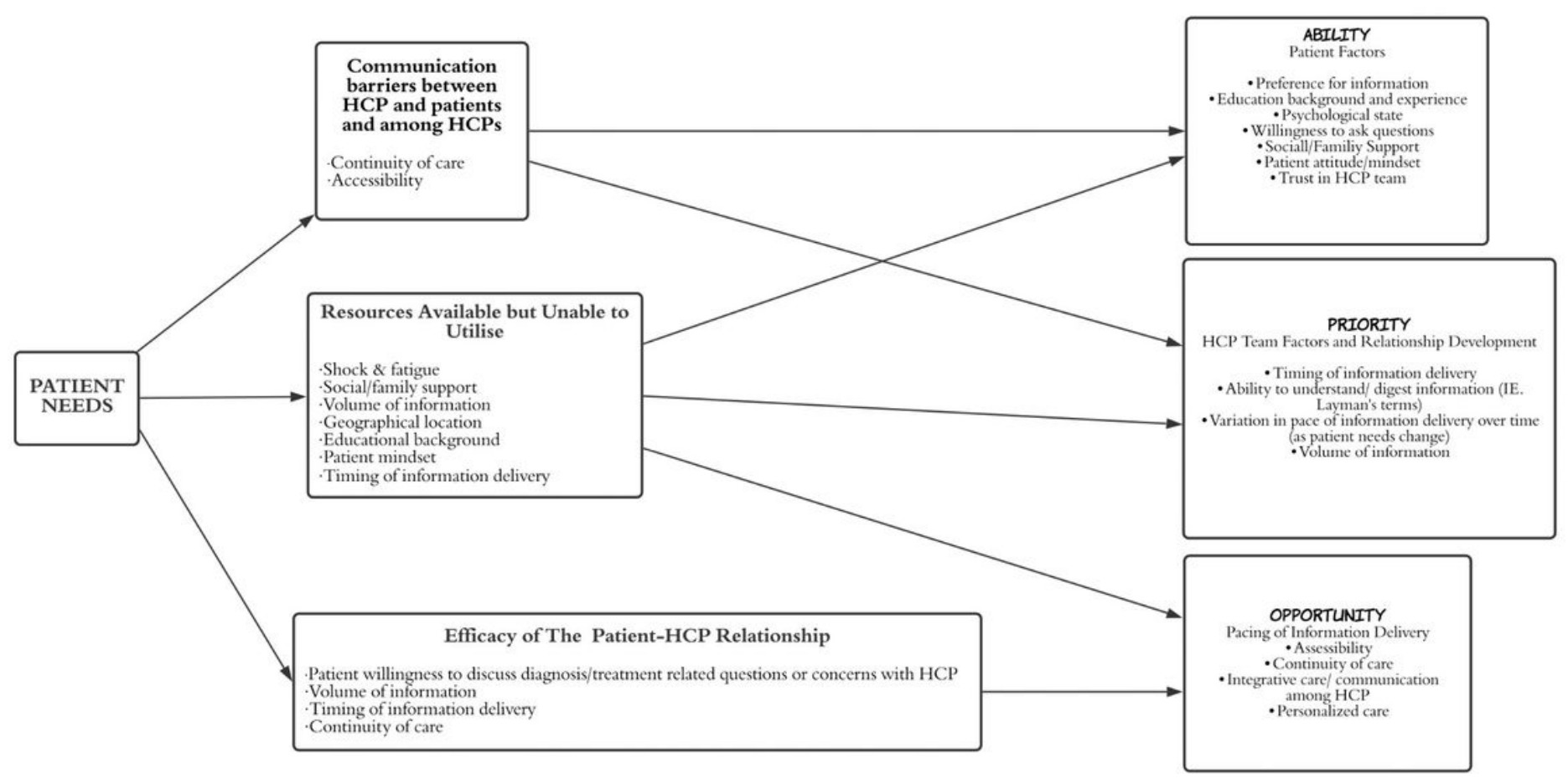

Figure 2

Consolidation of Primary Themes with Original Hypotheses

\section{Supplementary Files}

This is a list of supplementary files associated with this preprint. Click to download.

- SISCCMcDonnell.docx 